\title{
Representation of the visual field in the occipital striate cortex
}

\author{
Robert McFadzean, Donal Brosnahan, Donald Hadley, Erkan Mutlukan
}

\begin{abstract}
The representation of the field of vision in the human striate cortex is based on the Holmes map in which about $25 \%$ of the surface area of the striate cortex is allocated to the central 15 degrees of vision. Following the introduction of computed tomography of the brain, the accuracy of the Holmes map was apparently confirmed by clinical/radiological correlation, but a revision has been proposed by Horton and Hoyt based on a magnetic resonance imaging study of three patients with visual field defects due to striate lesions. They propose that the central cortical representation of vision occupies a much larger area. This study reviews the perimetric and imaging findings in a larger series of patients with striate cortical disease and provides support for the revised representation. The clinical phenomenon of macular sparing and its relation to representation of the macula at the occipital pole is also discussed.
\end{abstract}

(Br f Ophthalmol 1994; 78: 185-190)

The representation of the visual field in the occipital striate cortex was initially delineated by Inouye ${ }^{1}$ and subsequently by Holmes and Lister $^{2}$ in studies of wounded soldiers in the Russo-Japanese war (1904-1905) and the first world war (1914-1918). ${ }^{3}$ Thereafter Holmes devised his original 'schema' which gained widespread acceptance. ${ }^{4}$ In this diagrammatic outline of the striate cortex Holmes demonstrated representation of the contralateral hemifield of vision in each cerebral hemisphere, with the horizontal meridian occupying the base of the calcarine fissure and the vertical meridian demarcating the outer perimeter of the striate cortex. The macular region was represented posteriorly at the occipital pole, while the peripheral visual field occupied the anterior striate cortex in the region of the junction of the parieto-occipital and calcarine fissures. It was appreciated that the macular region extended over a relatively large part of the striate cortex and, using a planimeter, it has been calculated that $25 \%$ of the surface area of the striate cortex was attributed to the central 15 degrees of vision. ${ }^{5}$ Following the development of computed tomography (CT) of the brain, several authors confirmed this original concept when they found a good correspondence between visual field defects and the location of striate lesions on CT according to the Holmes 'schema' ${ }^{6-9}$ An activation study of the visual cortex using positron emission tomography (PET) scanning also supported the Holmes 'schema'. ${ }^{10}$

Furthermore Holmes believed that the macula was unilaterally represented at the occipital pole, ${ }^{2}$ although Inouye included a small representation of the ipsilateral macula in each occipital lobe following the discovery of macular sparing in some clinical cases.' Such bilateral representation of the macula has subsequently been invoked by a number of authors in primate animal experimental studies to explain the clinial phenomenon of macular sparing, ${ }^{11-15}$ although in other studies bilateral representation of the macula in the striate cortex did not occur. ${ }^{16-18}$ Clinically, owing to fixational eye movements of one to two degrees during perimetry, there must be at least three degrees of macular sparing to make the finding reliable using currently available perimetric techniques. ${ }^{19-22}$ However, the bilateral representation theory proposed in the above experimental studies is dependent on a nasotemporal overlap across the vertical meridian which is only 0.6 to 2 degrees wide. ${ }^{11} 15$

Recently the traditional Holmes hypothesis was challenged in a magnetic resonance scanning study ${ }^{5}$ of three patients with striate disease and a revised map of the representation of the visual field in the human striate cortex was produced in which the area serving central vision was expanded and the area devoted to peripheral vision reduced. Similarities to data from closely related non-human primate species were noted, in particular to electrophysiological studies of Old World primate genera, in which central vision occupied a large proportion of the striate cortex. ${ }^{16} 172324$ Indeed, in macaque monkeys the central 15 degrees of vision occupy about $70 \%$ of the total surface area of the striate cortex..$^{2324}$

Horton and Hoyt's revision of the classical Holmes 'schema' requires confirmation in a larger series of patients and the clinical phenomenon of macular sparing further elucidation. This paper attempts to address these two issues.

\section{Materials and methods}

Patients suspected of suffering from occipital cortical disease had a full neuro-ophthalmic examination including detailed perimetry. Goldmann dynamic and/or Humphrey's static threshold perimetry were used in the majority of cases, but if there was any doubt about the findings these were confirmed on the Bjerrum screen in a few cases. Imaging of the visual pathways, to confirm the presence of striate cortical disease and exclude any other lesion, was carried out using a CT tomoscan and/or 0.15 Tesla magnetic resonance (MR) scan. In some patients an initial planning scan was carried out in the sagittal plane to identify the oblique course of the calcarine fissure, which does not of course run in a straight line. Its oblique plane was 
Table 1 Pathological lesions $(n=26)$

\begin{tabular}{ll}
\hline & No of cases \\
\hline Infarction & 15 \\
Neoplasm & 5 \\
Haematoma & 3 \\
Cerebromalacia & 2 \\
Arteriovenous malformation & 1 \\
\hline
\end{tabular}

Table 2 Visual field defects $(n=26)$

\begin{tabular}{ll}
\hline & No of cases \\
\hline Complete homonymous hemianopia & 17 \\
Incomplete homonymous hemianopia & 5 \\
Discrete homonymous scotomas & 2 \\
Bilateral altitudinal & 2 \\
\hline
\end{tabular}

Table 3 Macular involvement $(n=17)$

\begin{tabular}{lc}
\hline & No of cases \\
\hline Sparing & 10 \\
Splitting & 6 \\
Sparing/splitting & 1 \\
\hline
\end{tabular}

Figure $1 T 2$ weighted (SE 2000/80) axial magnetic resonance section shows a left occipital infarct involving the anteromedial striate cortex, but sparing the posterior striate cortex.

Figure 2 Goldmann dymamic visual field shows a right homonymous hemianopia to within 10 degrees of central fixation using $12 e$ and I4e targets.
Table 4 Occipital poleloperculum sparing $(n=17)$

\begin{tabular}{ll}
\hline & No of cases ${ }^{\star}$ \\
\hline Macular sparing & $9 / 11$ \\
Macular splitting & $0 / 7$ \\
\hline
\end{tabular}

^One case demonstrated both macular sparing and splitting (case 5).

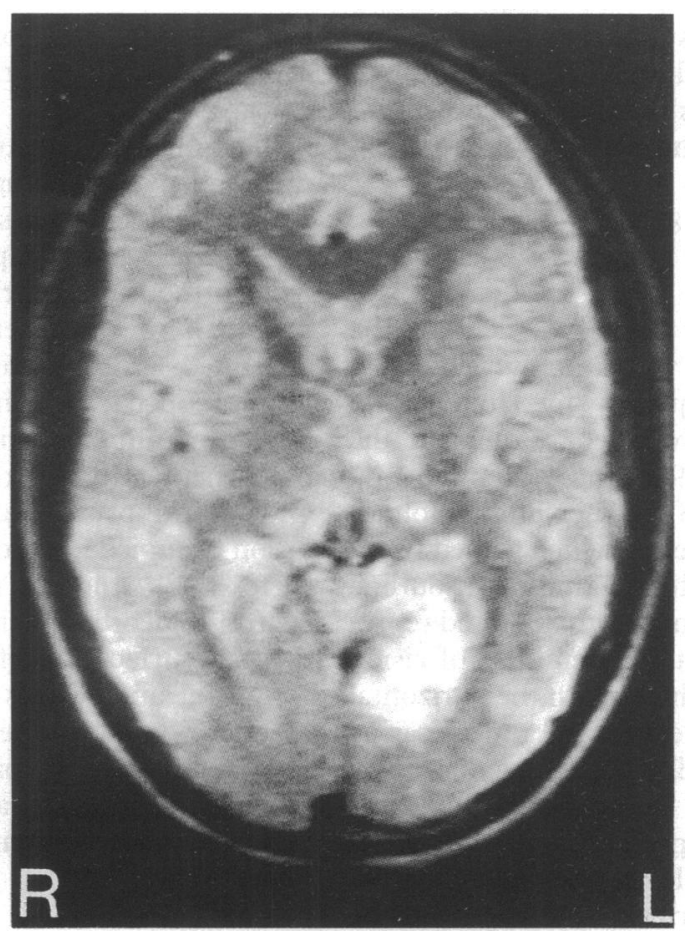

Figure $3 T 1$ weighted (IR 1600/40/400) parasagittal magnetic resonance section shows a left occipital infarct involving the superior bank of the striate cortex (arrowhead), but sparing the posterior striate cortex.

determined by drawing a straight line on the sagittal scan joining its anterior (at the junction with the parieto-occipital fissure) and posterior (at the occipital pole) limits. Subsequent scans were performed axially in the plane of the calcarine fissure or coronally at right angles to it. The imaging changes were then compared with the patient's visual fields and the expected visual fields according to the Holmes 'schema' and Horton and Hoyt's map.

\section{Results}

Occipital striate cortical disease was identified in 26 patients with an age range of 21-82 years (average 50 years) and a male to female ratio of 11:15. The majority of patients suffered from occipital infarction but there were also a number of other pathologies (Table 1). The visual field defects were recorded (Table 2) in which a complete homonymous hemianopia is defined as one which extends to within 10 degrees of central fixation, while an incomplete homonymous hemianopia lies beyond 10 degrees from central fixation. A blind patient presented with a macular sparing homonymous hemianopia and then lost the residual field a few days later due to presumed bilateral occipital infarctions.

Macular involvement - that is, within 10 degrees of central fixation, occurred in 17 patients, unilaterally in 16 patients, and bilaterally in one patient (see below). These were
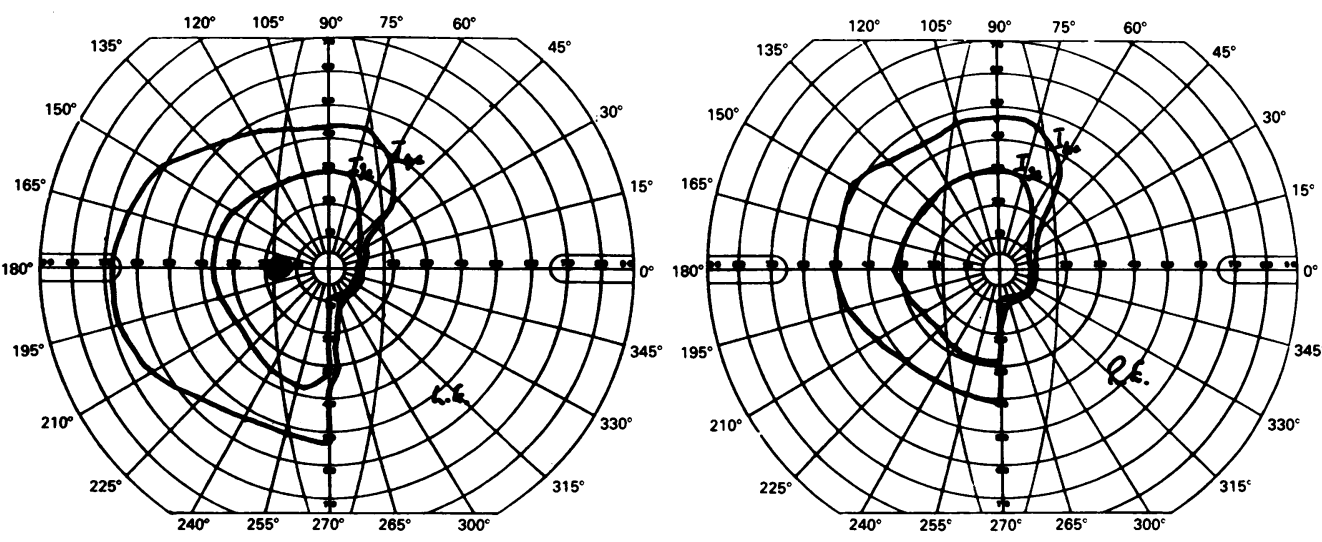


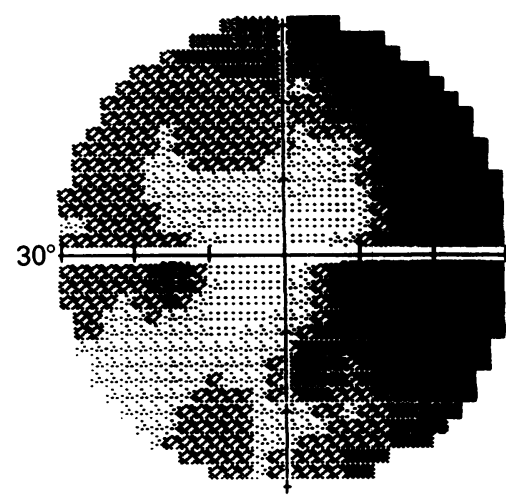

LE

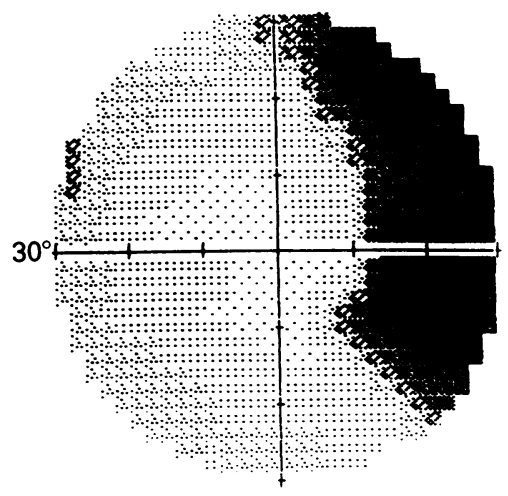

RE
Figure 4 Humphrey's static threshold central visual field (30-2 program) shows a right homonymous

hemianopia to within 10 degrees of central fixation.

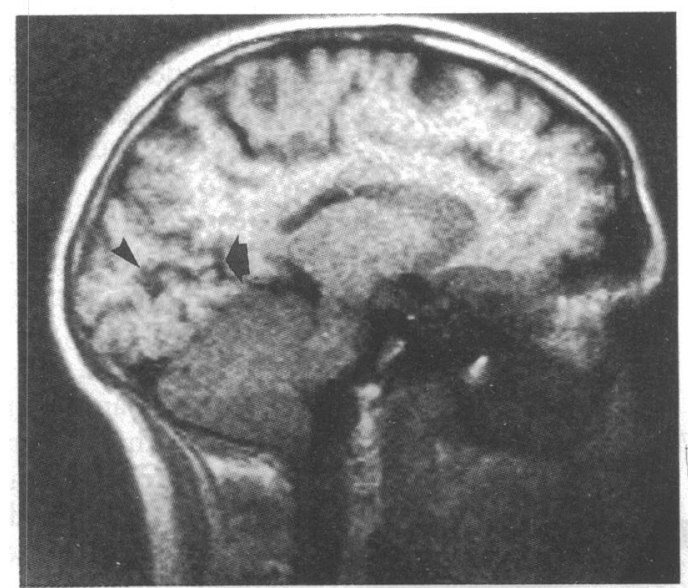

Figure 5 T1 weighted (IR 1600/40/400) parasagittal magnetic resonance section shows a right occipital infarct involving the superior bank of the striate cortex (arrowhead), but sparing the posterior striate cortex and the anterior striate cortex at the junction of the parieto-occipital and calcarine fissures (arrow).

divided into macular sparing - that is, outside 3 degrees of central fixation, and macular splitting - that is, within 3 degrees of central fixation, cases (Table 3). Imaging involvement of the occipital pole and operculum was then identified and compared with the perimetric abnormalities (Table 4). In two elderly patients with macular sparing it was not possible to identify precisely whether the occipital pole was or was not involved owing to movement artefacts on the scan.

Figure 6 Humphrey's static threshold central visual field (30-2 program) shows a left inferior homonymous quadrantanopia to within 6 degrees of central fixation.

\section{CASE ILLUSTRATIONS}

\section{Case 1}

A 21-year-old man developed a left occipital

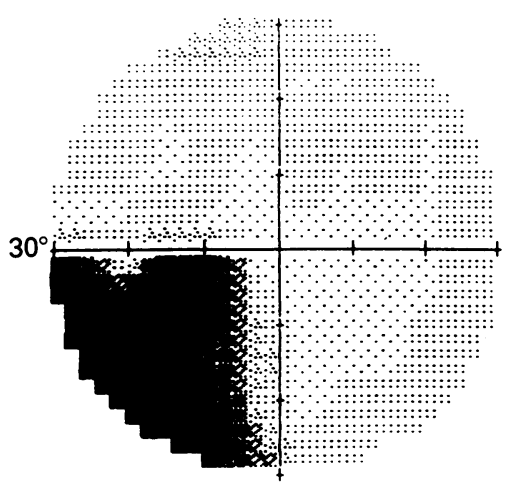

LE

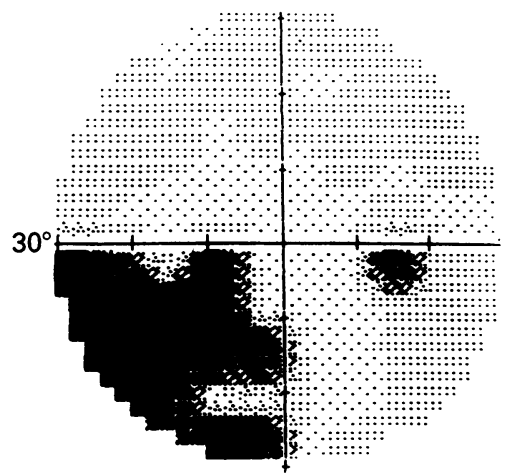

RE infarct following a head injury (Fig 1). According to Holmes this infarct should have produced a right homonymous hemianopia extending to within 60 degrees of fixation, while Horton and Hoyt predict a perimetric defect extending to within 20 degrees of fixation. In fact Goldmann dynamic perimetry showed a right homonymous hemianopia extending to within 10 degrees of central fixation (Fig 2).

\section{Case 2}

A 35-year-old woman developed a left occipital infarct (Fig 3). According to Holmes such a lesion would produce a right homonymous hemianopia extending to within 30 degrees of fixation, while Horton and Hoyt predict a field defect extending to within 12 degrees of fixation. Humphrey's static threshold perimetry showed a right homonymous hemianopia extending to within 10 degrees of central fixation (Fig 4).

\section{Case 3}

A 40-year-old man developed a right occipital infarct affecting the superior bank of the calcarine cortex (Fig 5). According to Holmes such a lesion would produce a left inferior homonymous quadrantanopia extending to within 30 degrees of fixation, while Horton and Hoyt predict a field defect extending to within 10 degrees of fixation. Humphrey's static threshold perimetry demonstrated a left inferior homonymous quadrantanopia extending to within 6 degrees of central fixation (Fig 6). This patient also demonstrated sparing of the left monocular temporal crescent with sparing of the portion of the superior bank of the right calcarine cortex adjacent to the parieto-occipital fissure. (Fig 7).

\section{Case 4}

A 56-year-old man developed a spontaneous right parieto-occipital haematoma without an underlying vascular malformation and subsequent cerebromalacia with involvement of the occipital pole and operculum (Fig 8). According to both Holmes and Horton and Hoyt such a lesion would produce a left macular splitting homonymous hemianopia, as in this case (Fig 9).

\section{Case 5}

A 48-year-old woman developed bilateral occipital infarcts after a stormy course following clipping of a ruptured anterior communicating artery aneurysm (Fig 10). According to Holmes such a lesion would produce a macular splitting left homonymous hemianopia and a macular sparing right homonymous hemianopia extending to within 15 degrees of fixation, while according to Horton and Hoyt such a lesion would produce a macular splitting left homonymous hemianopia with a macular sparing right homonymous hemianopia extending to within 2.5 degrees of fixation. Charting on the Bjerrum screen in this case showed a macular splitting left homonymous hemianopia and a macular sparing right homonymous hemianopia extending to within three degrees of central fixation (Fig 11). 


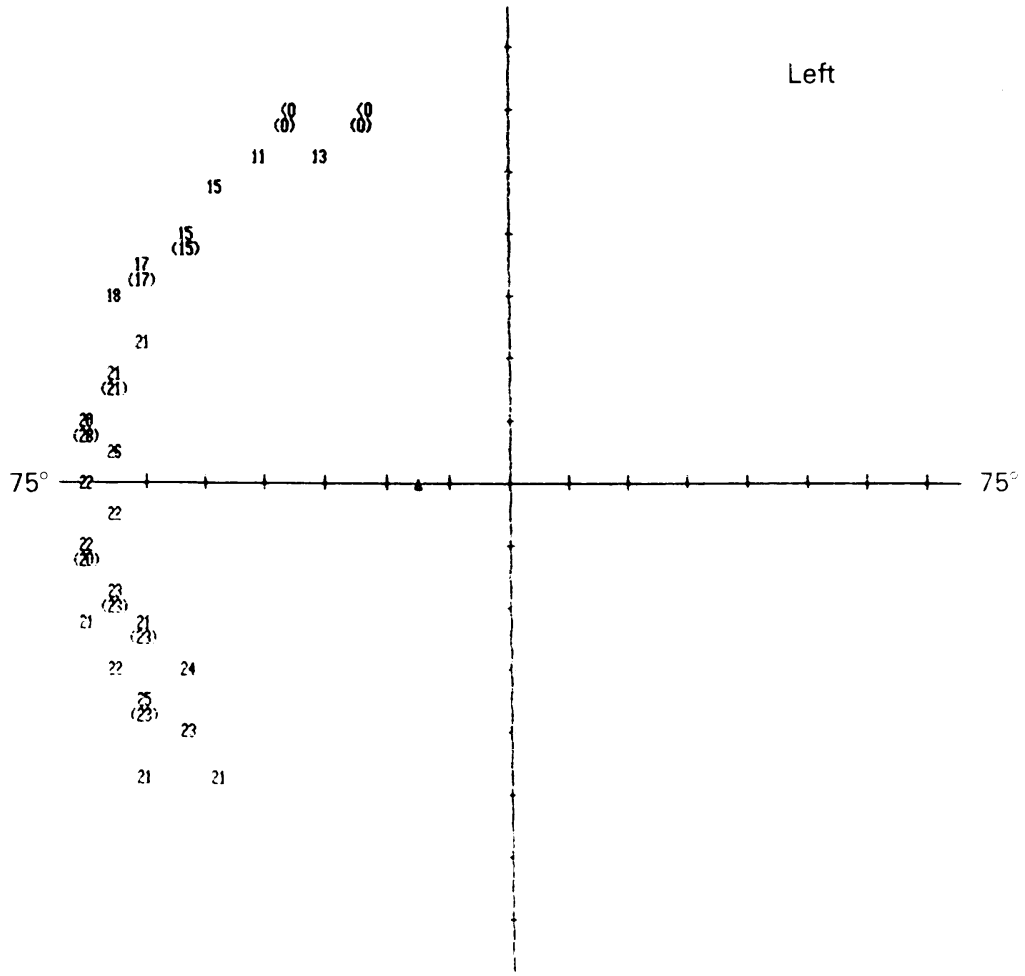

Figure 7 Humphrey's static threshold perimetry (temporal crescent program) shows sparing of the left monocular temporal crescent.

Figure 8 Tl weighted (IR 1600/40/400) oblique axial magnetic resonance section parallel to the plane of the calcarine fissure shows cerebromalacia of the right occipital lobe including the operculum.

Figure 9 Humphrey's static threshold central visual field (30-2 program) shows a left macular splitting homonymous hemianopia.

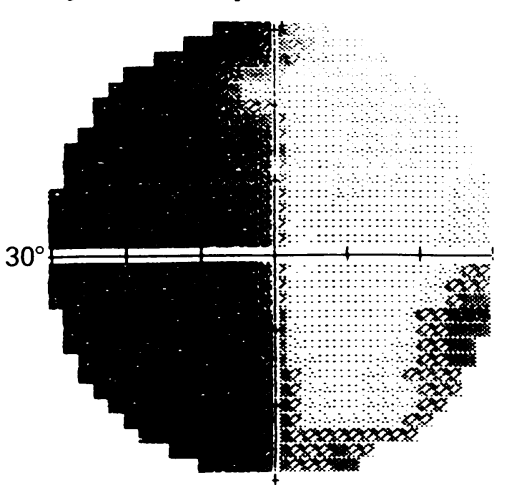

LE
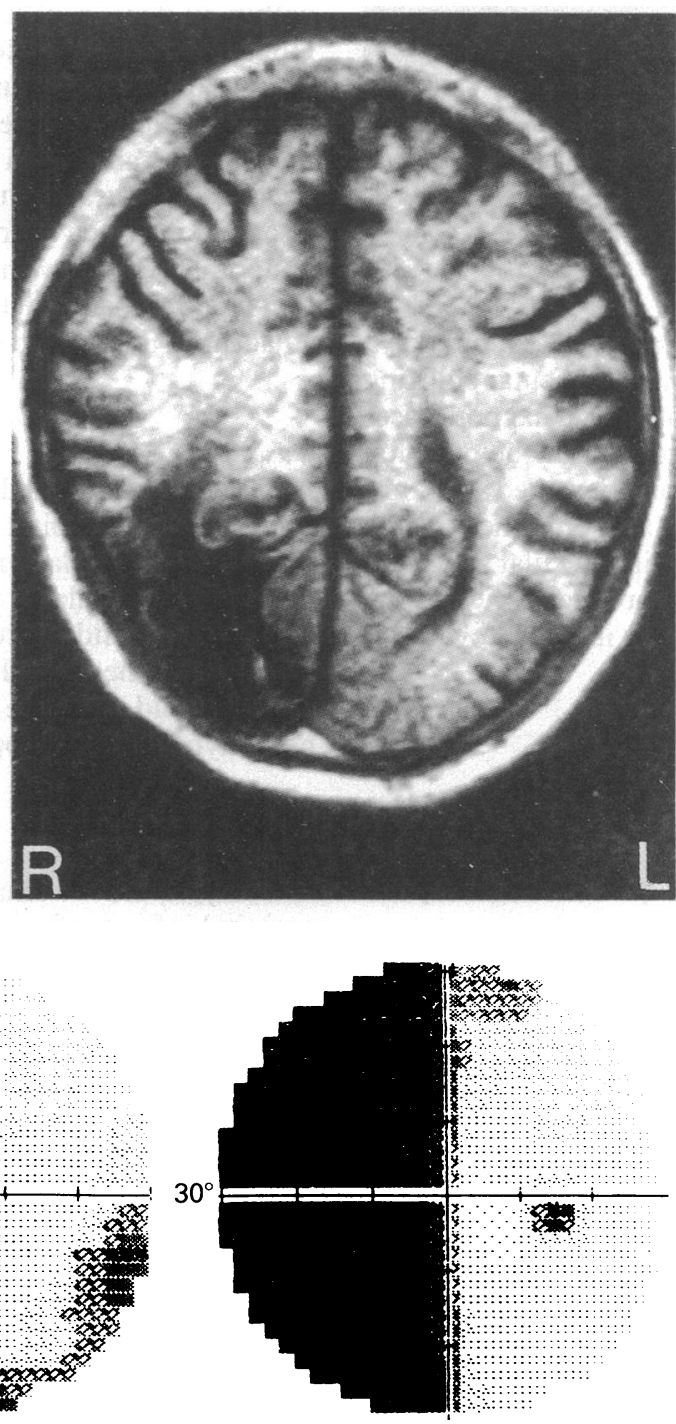

RE

\section{Discussion}

These cases and the others reviewed in this series clearly demonstrate that Horton and Hovt's concept $^{5}$ of an expanded area serving central vision with a reduced area devoted to peripheral vision can be confirmed in a larger series of patients. Although there are considerable variations in the surface area and extent of the striate cortex in humans, the findings from the present study indicate that the central 10 degrees of visual field are represented by at least $50-60 \%$ of the posterior striate cortex. Cases 1 and 2 clearly demonstrate that at least $50 \%$ of the posterior striate cortex is devoted to the central 10 degrees of visual field. The field defect in case 3 extends to within 6 degrees of fixation while a similarly large area of posterior striate cortex is preserved, and in addition, sparing of the monocular temporal crescent corresponds to sparing of the striate cortex adjacent to the parieto-occipital/ calcarine fissure junction. Case 4 illustrates macular splitting dependent on involvement of the occipital pole and operculum, while in case 5 sparing of the left occipital pole and operculum results in sparing of the right central three degrees of vision, but involvement of the right occipital pole and operculum causes loss of the left central three degrees of vision. The latter case clearly demonstrates both macular sparing and macular splitting dependent on the integrity of the occipital pole and operculum.

Indeed these cases suggest that Horton and Hoyt $^{5}$ may have slightly underestimated the extent of the central 15 degrees of vision on the posterior striate cortex, although variations in local anatomy might to some extent account for this. ${ }^{35}$ Our findings in the human striate cortex are compatible with microelectrode recordings in macaque striate cortex ${ }^{232}$ in which studies of linear and areal magnification factors concluded that the central 10 degrees of vision was represented by between $55-60 \%$ of the surface area of the striate cortex. In addition the pattern shift visual evoked potential is largely a reflection of macular vision ${ }^{26}$ with $60 \%$ of the amplitude of the waveform being generated by the central eight degrees of vision. Such a finding is compatible with the concept that a large part of the occipital pole, from which most of the visual evoked potential recording is derived, represents central vision.

It may seem surprising that the original Holmes 'schema' was confirmed by CT and PET studies. . $^{610}$ The CT scans, however, were carried out in the customary orbito-meatal plane which slices through the calcarine fissure obliquely and therefore does not give an accurate representation of the local anatomy. An activation study of the visual cortex using PET scanning ${ }^{10}$ was carried out in the anterior/posterior commissural line and was therefore subject to similar morphological misinterpretation. The calcarine fissure, although taking a variable course, does run obliquely in an anterosuperior direction from the occipital pole to the junction of the parietooccipital and calcarine fissures. Therefore an initial sagittal planning MR scan, as in this study, to identify the orientation of the calcarine fissure with sequential scans axial and coronal to the plane of the calcarine fissure give a much 
Figure $10 \quad T 2$ weighted (SE 2000/80) axial magnetic resonance section shows bilateral occipital infarcts, involving the occipital pole and operculum on the right side but sparing these structures on the left side. In addition there are right frontal and temporal infarcts.

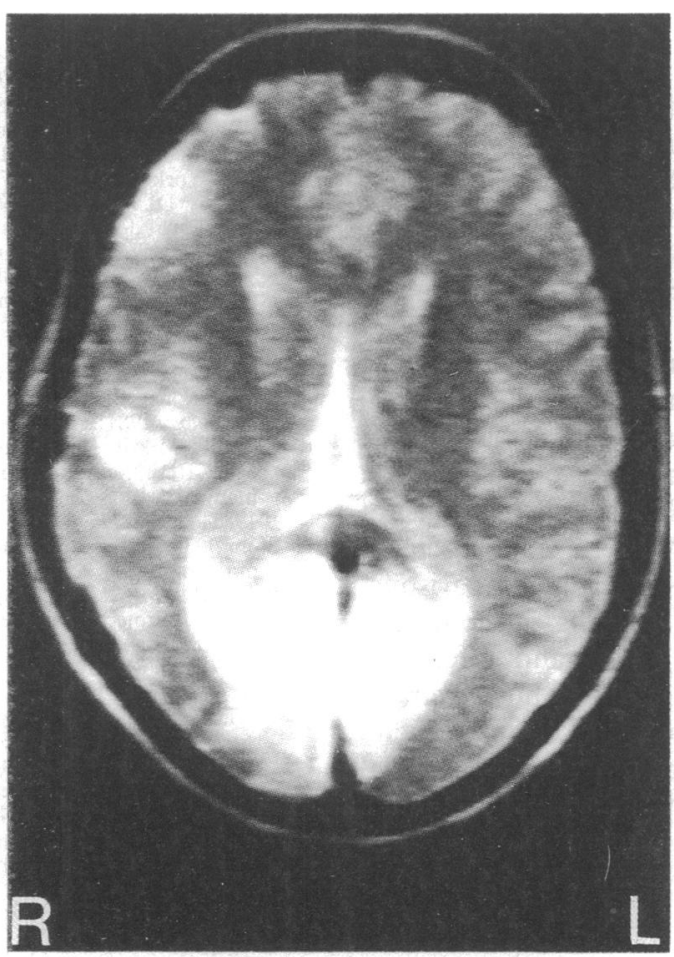

better impression of the local anatomy. Nevertheless, it is important to be cautious in relating the anatomical extent of a lesion on an MR scan to the functional perimetric findings, as the former simply outlines disturbances of water content and distribution within tissues without necessarily implying neuronal death, while the latter is a subjective determination of variation in function at one point in time. Clearly pathological verification of the imaging/perimetric findings is essential before precise determinations can be made, but an approximate evaluation can be obtained from the cases reported here and by others.

Indeed, based on the imaging findings, it is now possible clinically to classify striate lesions into anterior, intermediate, and posterior. Anterior lesions lie adjacent to the parietooccipital fissure and affect the monocular temporal crescent of the contralateral visual field. This area has been shown to constitute less than $10 \%$ of the total surface area of the striate

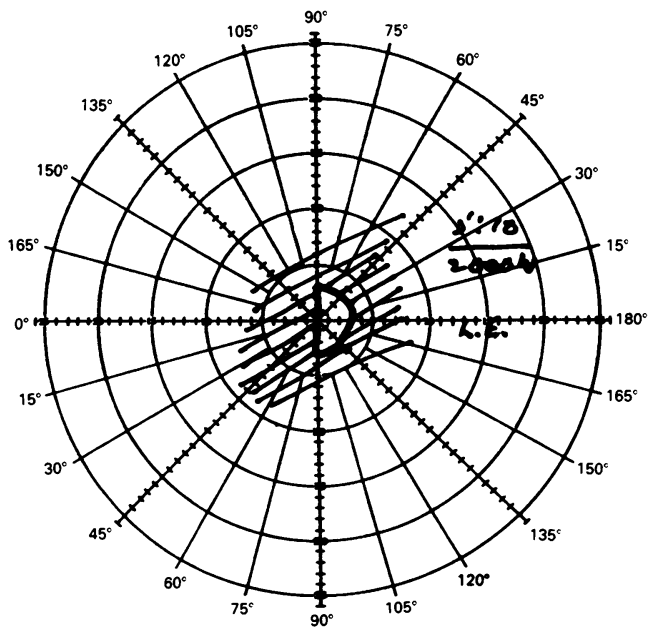

cortex. ${ }^{27}$ Posterior lesions are located in the posterior $50-60 \%$ of the striate cortex, including the occipital pole and operculum, and affect macular vision - that is, the central 10 degrees in the contralateral hemifield. Intermediate lesions lie between the anterior and posterior confines and affect from 10 to 60 degrees in the contralateral hemifield.

The clinical phenomenon of macular sparing has generated much discussion since Inouye and Holmes's original publications. ${ }^{12}$ The findings in this study clearly demonstrate that macular splitting occurs when the occipital pole and operculum are involved by the lesion and macular sparing occurs when there is sparing of these structures. Unfortunately, in two of our elderly patients with macular sparing it was not possible to come to a definite decision about involvement of the occipital pole on imaging owing to movement artefacts during scanning.

Attempts to explain the clinical phenomenon of macular sparing on the basis of bilateral representation of the macula with a nasotemporal overlap ${ }^{11-15}$ found in electrophysiological studies in non-human primates, are unsatisfactory, as the extent of the overlapping retinal ganglion cells would allow only one to two degrees of macular sparing. In practice, because of fixational eye movements of one to two degrees during perimetry ${ }^{19-22}$ it is necessary to detect at least three degrees of macular sparing in order to confirm the clinical phenomenon.

The explanation for the clinical phenomenon of macular sparing is almost certainly to be found in a consideration of the blood supply of the occipital pole and operculum which lie in a watershed zone between the posterior and middle cerebral arteries. There is a considerable variation in the course and distribution of the arteries supplying the striate corte $x^{28}$ but in $50 \%$ of normal brains the calcarine branch of the posterior cerebral artery supplies the entire striate cortex. In the remainder, the occipital pole and operculum are supplied by the posterior temporal or parieto-occipital branch of the posterior cerebral artery or an occipital branch of the middle cerebral artery. In the former situation a calcarine artery infarct would result in a macular splitting homonymous hemianopia but in the latter a similar infarct would allow a

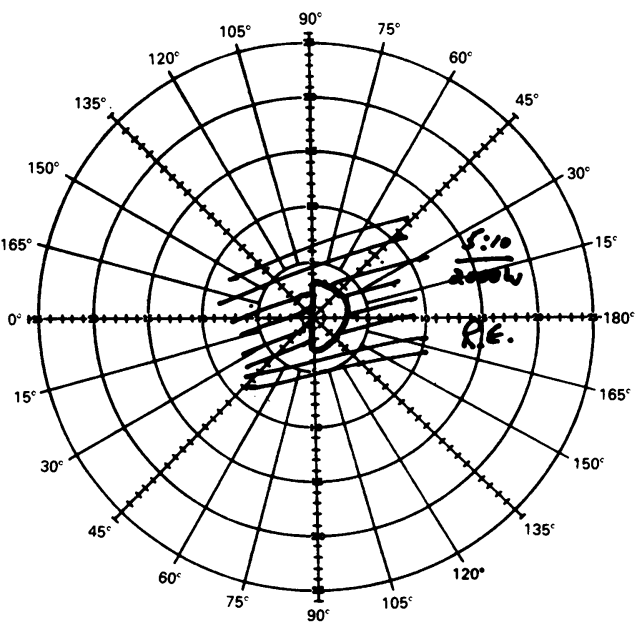

Figure 11 Bjerrum central visual field shows a macula splitting left homonymous sparing right homonymous hemianopia using 5 and 10 $\mathrm{mm}$ white target at 2 metres. 
macular sparing homonymous hemianopia owing to a collateral circulation from the posterior temporal or parieto-occipital branch of the posterior cerebral artery or an occipital branch of the middle cerebral artery. This simple anatomical explanation has been borne out in clinical practice in this series and confirms Holmes' original hypothesis that the macula was unilaterally represented.

Although Holmes's original concept of the representation of the visual field in the occipital striate cortex was simply a 'schema', subsequent students of this subject have failed to seek satisfactory clinicopathological correlations of his early observations. Modern imaging techniques permit perimetric-imaging comparisons, but the requirement for histological confirmation of the anatomical extent and effects of clinical striate lesions remains. The advent of activation studies of the occipital cortex by echo planar imaging may provide further spatial resolution of the central visual field representation. ${ }^{29} 30$

\section{Conclusion}

This study confirms Horton and Hoyt's revised map of the representation of the visual field in the occipital striate cortex with the central 10 degrees occupying at least $50-60 \%$ of the striate cortex posteriorly and the more peripheral visual field a correspondingly reduced area. These findings are compatible with electrophysiological studies in Old World primates. Lesions of the striate cortex can now be classified into anterior, intermediate, and posterior locations based on imaging findings and the corresponding visual field defeets identified on perimetry. The explanation for the clinical phenomenon of macular sparing lies in the variations in the blood supply of the occipital pole and operculum and it is not necessary to invoke bilateral representation of the macula to explain this clinical finding.

This paper is based on an oral presentation at the IX This paper is based on an oral presentation at the IX
International Neuro-ophthalmology Symposium, Williamsburg, International Neuro-ophthalm

The authors wish to thank their consultant neurological and neurosurgical colleagues at the Institute of Neurological Sciences for referring these patients, Ms Alison Buchanan, head orthoptist, for assistance with the perimetry, Mrs June Cunningham, medical photographer, for the illustrations, and Mrs Rosemary Tracey, secretary, for careful preparation of this manuscript.

1 Inouye T. Die Sehstorungen bei Schussverletzungen der kortikalen Sehsphare. Leipzig, Germany: W Engelmann, 1909.

2 Holmes G, Lister WT. Disturbances of vision from cerebral lesions with special reference to the cortical representation of the macula. Brain 1916: 39: 34-73.

3 Glickstein M. The discovery of the visual cortex. Sci Am 1988; 259: 84-91.

4 Holmes G. Disturbances of vision by cerebral lesions. $\mathrm{Br} \mathcal{F}$ Ophthalmol 1918; 2: 353-84.
5 Horton JC, Hoyt WF. The representation of the visual field in human striate cortex: a revision of the classic Holmes map. Arch Ophthalmol 1991; 109: 816-24.

6 Orr LS, Schatz NJ, Gonzalez CF, Savino PJ, Corbett JJ. Computerised axial tomography in evaluation of occipital lobe lesions. In: Smith JL, ed. Neuro-ophthalmology update. New York: Masson, 1977: 351-67.

7 McAuley DL, Russell RWR. Correlation of CAT scan and visual field defects in vascular lesions of the posterior visual visual field defects in vascular lesions of the posterior visual
pathways. F Neurol Neurosurg Psychiatry 1979; 42: 298-311.

pathways. F Neurol Neurosurg Psychiatry 1979; 42: 298-311.
8 Kattah JC, Dennis P, Kolsky MP, Schellinger D, Cohan SL Computed tomography in patients with homonymous visual field defects - a clinico-radiologic correlation. Comput Tomogr 1981: 301-12.

9 Spector RH, Glaser JS, David NJ, Vining DQ. Occipital lobe infarctions: perimetry and computed tomography. Neurology 1981; 31: 1098-106.

10 Fox PT, Miezin FM, Allman JM, Van Essen DC, Raichle ME. Retinotopic organisation of human visual cortex mapped with positron emission tomography. 7 Neurosci 1987; 7: 913-22

11 Stone J, Leicester J, Sherman SM. The nasotemporal division of the monkey's retina. $\mathcal{F}$ Comp Neurol 1973; 150: 333-48.

12 Bunt AH, Minckler DS, Johanson GW. Demonstration of bilateral projection of the central retina of the monkey with horseradish peroxidase neuronography. F Comp Neurol horseradish peroxidas 1971 171: 619-30.

13 Bunt AH, Minckler DS. Foveal sparing: new anatomical evidence for bilateral representation of the central retina. Arch Ophthalmol 1977; 95: 1445-7.

14 Leventhal AG, Ault SJ, Vitek DJ. The nasotemporal division in primate retina: the neural basis of macular sparing and splitting. Science 1988; 240: 66-7.

15 Fukuda Y, Sawai H, Watanabe M, Wakakuwa K, Morigiwa $K$. Nasotemporal overlap of crossed and uncrossed retinal ganglion cell projections in the Japanese monkey (Macaca fuscata). $\mathcal{F}$ Neurosci $1989 ; 9$ : 2353-73.

16 Talbot SA, Marshall WH. Physiological studies on neural mechanisms of visual localization and discrimination. $A m \mathcal{F}$ mechanisms of visual localization

17 Dow BM, Vautin RG, Bauer R. The mapping of visual space onto foveal striate cortex in the macaque monkey. $\mathcal{F}$ Neurosci 1985; 5: 890-902.

18 Tootell RBH, Switkes E, Silverman MS, Hamilton SL. Functional anatomy of macaque striate cortex, II: retinotopic organisation. $\mathcal{F}$ Neurosci $1988 ; 8$ : 1531-68.

19 Jung R, Kornhuber HH. Results of electronystagmography in man: the value of optokinetic, vestibular and spontaneous nystagmus for neurologic diagnosis and research. In: Bender MB, ed. The oculomotor system. New York: Hoeber Medical Division, Harper and Row, 1964: 428-82.

20 Winterson BJ, Collewign H. Microsaccaddes during finely guided visuomotor tasks. Vision Res 1976; 16: 1387-90.

21 Dell'Osso LF, Abel LA, Daroff RB. 'Inverse latent' macro square-wave jerks and macro saccadic oscillations. Ann square-wave jerks and

22 Herishanu YO, Sharpe JA. Normal square wave jerks. Invest Ophthalmol Vis Sci 1981; 20: 268-72.

23 Daniel PM, Whitteridge D. The representation of the visual field on the cerebral cortex in monkeys. F Physiol 1961; 159: 203-21.

24 Van Essen DC, Newsome WT, Maunsell JHR: The visual field representation in striate cortex of the macaque monkey: asymmetries, anisotropies and individual variability. Vision Res 1984; 24: 429-48.

25 Stensaas SS, Eddington DK, Dobelle WH. The topography and variability of the primary visual cortex in man. and variability of the primary

26 Yiannikas C, Walsh JC. The variation of the pattern shift visual evoked response with the size of the stimulus field. visual evoked response with the size of the stimulus
Electroencephalogr Clin Neurophysiol 1983; 55: 427-35.

27 Horton JC, Dagi LR, McCrane EP, de Monasterio FM Arrangement of ocular dominance columns in human visua cortex. Arch Ophthalmol 1990; 108: 1025-31

28 Smith CG, Richardson WFG. The course and distribution of the arteries supplying the visual (striate) cortex. Am $\mathcal{f}$ Ophthalmol 1966; 61: 1391-6.

29 Belliveau JW, Kennedy DN, McKinstry RC, Buchbinder BR, Weisskoff RM, Cohen MS, et al. Functional mapping of the human visual cortex by magnetic resonance imaging. Science 1991; 254: 716-9.

30 Kwong KK, Belliveau JW, Chesler DA, Goldberg IE, Weisskoff RM, Poncelet BP, et al. Dynamic magnetic resonance imaging of human brain activity during primary resonance imaging of human brain activity during primary sensory 